\title{
Estrategias de comunicación política: sentidos del patrimonio y el turismo en Córdoba (2010-2018)
}

\author{
Strategies of political communication: heritage and tourism senses \\ in Córdoba (2010-2018)
}

María Belén Espoz Dalmasso belenespoz@gmail.com

http://orcid.org/0000-0003-0601-8108

Centro de Investigaciones y Estudios sobre Cultura y Sociedad;

Universidad Nacional de Córdoba/ Consejo Nacional de Investigaciones Científicas y Técnicas (Argentina)

María Lis del Campo delcampo.marialis@gmail.com

http://orcid.org/0000-0001-5669-5057

Escuela de Nutrición; Facultad de Ciencias Médicas; Universidad Nacional de Córdoba (Argentina)

\section{Resumen}

El presente artículo tiene por objeto analizar el sentido de las intervenciones patrimoniales en el contexto urbano cordobés en la última década con el objeto de instalar: a. al turismo como organizador social que expresa nuevas modalidades de acumulación por desposesión; b. al patrimonio y al turismo como estrategias de comunicación política del Estado. Para ello 
daremos cuenta de las principales transformaciones en materia pública y privada orientadas a la construcción del patrimonio de la ciudad y su articulación con lo que se reconoce como procesos de patrimonialización, gentrificación y turistificación. Se vuelven productivas en esta dirección dos categorías para comprender el alcance e incumbencia de estos procesos: el embellecimiento estratégico (Benjamin; Debord) y acumulación por desposesión (Marx; Harvey; Bensäid). Analizamos el caso del cuarteto y la gastronomía cordobesa para establecer en las conclusiones el lugar clave de la comunicación como estrategia que busca coagular las diversas conflictividades que emergen en el marco de las intervenciones urbanas vinculadas al desarrollo del sector turístico y la puesta en valor patrimonial.

Palabras clave: Sentidos; patrimonio; turismo; comunicación; estado.

\section{Abstract}

The purpose of this article is to analyze the meaning of patrimonial interventions in the Cordoba urban context in the last decade with the aim of installing: a. tourism as a social organizer that expresses new forms of "accumulation by dispossession"; b. Heritage and tourism as strategies of State political communication. For this we will give an account of the main public and private transformations aimed at the construction of the urban heritage of the city and its articulation with what is recognized as patrimonialization, gentrification and turistification processes. Two categories become productive in this direction to understand the scope and incumbency of these processes: strategic embellishment (Benjamin, Debord) and accumulation by dispossession (Marx, Harvey, Bensäid). We analyze the case of the Cordoba quartet and gastronomy to establish in the conclusions the key place of communication as a strategy that seeks to coagulate the various conflicts that emerge within the framework of urban interventions linked to the development of the tourism sector and the enhancement of heritage value.

Keywords: Senses; heritage; tourism; communication; state.

En la última década, el 'turismo' (1) aparece como encuadre fundamental de múltiples experiencias urbanas y rurales, instalándose como una de las claves del desarrollo sustentable regional. El patrimonio como argumento que vincula ciertas prácticas de restauración, revalorización o preservación de bienes materiales e inmateriales a un territorio cultural 
determinado socio-históricamente, también emerge como eje transversal en la discursividad política contemporánea vinculada al sector. La implementación del Plan Estratégico de Turismo Sustentable por regiones llevado adelante desde 2006 por la provincia, el Plan estratégico de Gestión Turística y diferentes estrategias del gobierno municipal en torno al patrimonio y turismo urbano, aparecen como encuadre socio-ideológico (Espoz, 2013) de diferentes intervenciones en Córdoba donde la impronta de marca-país, marca-ciudad emerge con claridad en tanto estrategia de comunicación política.

A los corredores turísticos estratégicos establecidos por el plan Director de la Ciudad de Córdoba (2008) se suman diferentes emprendimientos inmobiliarios y urbanísticos en que argumento para su realización se articula con la generación de lugares cuyo valor para el mercado turístico aparece como indisociable. En este marco -y con resistencias- se crea en la última década el Instituto de Planificación Metropolitana (IPLAM provincial) e IPLAM ciudad como herramientas de gestión de carácter público-privado orientadas a la planificación integral de la ciudad. Ambos remarcan la importancia del desarrollo de políticas públicas sostenidas con base en "la generación de estudios de nivel científico y formulación de propuestas estratégicas sustentadas (...)". Actualmente, el Plan Director Córdoba 2020 va reperfilando por zonas los espacios donde el capital orientado al turismo se espacializa/especializa. En consecuencia, nos interrogamos sobre la articulación de ciertos procesos de patrimonialización, gentrificación y turistificación como entramado de acciones que impactan directamente en los territorios modificando condiciones habitacionales y relaciones sociales.

Nos proponemos reflexionar en torno a dichos procesos buscando evidenciar, para el caso cordobés: a. continuidades y rupturas entre los procesos de turistificación, gentrificación y patrimonialización y su impacto en la generación de valor (económico, cultural, ideológico) de los territorios; b. el lugar del turismo en la discursividad política cordobesa en lo que respecta a poner en valor al patrimonio local. La estrategia expositiva será la siguiente: desarrollaremos teóricamente el lugar que los procesos de 'gentrificación', 'turistificación' y 'patrimonialización' tienen en el marco de la reconfiguración del capital a escala global. Para ello retomamos la noción de "acumulación por desposesión" desarrollada por Harvey (2004) para evidenciar las continuidades en torno a la generación de valor de y en los territorios en escenarios urbanos contemporáneos. Luego, expondremos la particular relación entre los tres procesos referidos y las intervenciones urbanas realizadas en la capital cordobesa en los últimos años, encontrando un argumento general en el 'patrimonio urbano' como modalidad estratégica del Estado y del mercado para configurar modalidades particulares de generación de valor que se orientan a dos públicos específicos: 'pobladores' y 'turistas'. Por último, intentaremos dar cuenta del lugar 
del turismo como estrategia de comunicación política en los escenarios descriptos: aquí, recurriremos al campo conflictual para dar cuenta de la tensión y disputa de sentidos atribuidos a los espacios que señalan formas alternas ( $y$ a veces contradictorias) de conformación de valores en los territorios.

\section{Urbanismo estratégico: continuidades y rupturas en la generación de valor de los territorios}

Desde hace una década indagamos en las principales transformaciones urbanas en la ciudad de Córdoba y cómo estas se conectan con las dinámicas de interacción social. La metáfora de Sennet (1997) sobre carne y piedra nos sirvió como guía para comprender de qué manera el orden urbano señala una particular estructuración social que asigna lugares a cuerpos. Fuimos detectando diferentes procesos que atraviesan la toma de decisiones (conformación de formas de hábitat, planificación de la circulación, focalización de obras para el disfrute o la memoria, etc.) tanto del Estado como del Mercado y los organizamos, por su especificidad y en términos analíticos, en tres: gentrificación, turistificación, y patrimonialización. Ninguno se da por separado y de manera aislada, sino que conviven como orientaciones prácticas puntuales en fases de intervención territorial localizadas (2).

El problema del espacio ha generado bibliografía vasta y diversa. El problema del cuerpo corre con la misma suerte en términos de la amplia producción que busca darle asidero teórico y metodológico. Por ello, en el marco del objetivo propuesto para este trabajo, seguimos dos pistas teóricas para pensar la trama que ata cuerpos y espacios: la noción de "embellecimiento estratégico" benjaminiana y la de "urbanismo como Ciencia de Estado" en Debord. La primera, permite instalar la necesidad de una mirada histórica en los procesos de configuración de la materialidad-soporte de lo 'estrictamente urbano' con relación al conflicto social: al mirar el París de Haussman, Benjamin entendía cómo la propia forma de la ciudad servía a intereses muy diversos de cara al conflicto entre Estado y clases (3). La "calle", como expresión de las formas de circulación deseable de París a comienzos de siglo XIX, mostraba el predominio de un tipo de experiencia que privilegiaba el sentido de la vista sobre el oído para reconocer y clasificar a la multitud (vendedores-clientes; patrones-empleados, competidores), a la vez que indicaba cómo ese espacio-tiempo podía convertirse a partir de un uso "inesperado" (un accidente, un incendio, una barricada) en un lugar que "reúne a gentes libres de determinación de clases" (Benjamín, 1972: 79). 
En este punto, la calle es un principio de indeterminación que posibilita formas de expresión del conflicto inabarcables por la estadística moderna: lo que el acontecimiento convoca y genera es imposible de ser determinado, aunque, como observaremos en el devenir cada vez más estratégico del urbanismo, sí condicionado/controlado. El 'embellecimiento estratégico' de Paris modificó - de la mano al desarrollo del capital- las formas de pensar la ciudad, donde el par cuerpos enclasados/conflictividad social se estructuró como eje de ordenación política, constituyéndose en un claro antecedente del urbanismo moderno. El carácter represivo de las decisiones urbanísticas de Haussmann no pasaba desapercibido como medidas de disciplinamiento del espacio y control social. Benjamín va más allá al entenderlas también como estetización política: los fines prácticos y estéticos de las obras (recordemos que eran cubiertas hasta su inauguración) funden intereses económicos y militares, pero cuyo objeto fue la destrucción generalizada de la ciudad tal y como sus pobladores la (re)conocían: la ciudad se convertía en 'obra de arte pública' (4). Es precisamente este carácter espectacular el que persiste en el presente como forma comunicativa de las intervenciones locales.

Ya en el París del siglo XX, más precisamente en la antesala del mayo francés, Guy Debord encontraba la exacerbación de esa lógica al comprender al urbanismo como "Ciencia de Estado". Aquí el urbanismo es identificado con un modo generalizado y racional de planificación de la vida, donde aparece un (y solo uno) modo de vivir la ciudad despojado de cualquier implicancia afectiva con ella de manera individual o colectiva. Toda diversidad parece subsumirse y/o adecuarse a un solo deseo de forma de vida (ideológicamente planteado): el burgués. El orden de las piedras emergía como un deseo ajeno a aquellos que constituían la ciudad y no podían percibir en ella más que una función: la productiva. Así, el Estado burgués surge como la manifestación del deseo (totalitario) del capital:

El movimiento constante de monopolización de la vida histórica por el Estado de la monarquía absoluta, forma de transición hacia la dominación completa de la clase burguesa, hace aparecer en su verdad lo que es el nuevo tiempo irreversible de la burguesía. Es al tiempo de trabajo, por primera vez librado de lo cíclico, al que la burguesía está ligada. El trabajo se ha convertido con la burguesía en trabajo que transforma las condiciones históricas. La burguesía es la primera clase dominante para quien el trabajo es un valor. Y la burguesía que suprime todo privilegio, que no reconoce ningún valor que no derive de la explotación del trabajo, ha identificado precisamente con el trabajo su propio valor como clase dominante y ha hecho del progreso del trabajo su propio progreso. La clase que acumula las mercancías y el capital modifica continuamente la naturaleza modificando el trabajo mismo, desencadenando su productividad (...) (Debord, [1967]1995). 
Este movimiento materializado en la transformación de Haussmann identificado por Benjamín décadas antes, se expresa en el París de Debord como el dominio absoluto del deseo mercantil en una forma de ciudad regida por la separación/segregación. Aislamiento que aparece suturado ideológicamente en el espectáculo (5) consolida la imposibilidad por generar una experiencia urbana unitaria de carne y piedra. A cada habitante, despojado de su deseo con respecto a la ciudad, solo le queda una preocupación: trabajar, trabajar, trabajar (6). Mientras la ciudad parece auto-regenerarse a partir de su propia rentabilidad, ganando terreno como un sujeto más del juego político entre el Estado y el Mercado.

La subsunción de tiempo en el espacio fue la antesala que posibilitó toda una serie de operaciones de generación de (plus) valor en la constitución de la ciudad 'moderna' (7) y que continúan en la metamorfosis de la vida urbana actual. Hablamos del determinante que encuentra Harvey (2003) (8) al pensar la historia de una geografía capitalista, 'la acumulación por desposesión'.

Una mirada más atenta de la descripción que hace Marx de la acumulación originaria revela un rango amplio de procesos. Estos incluyen la mercantilización y privatización de la tierra y la expulsión forzosa de las poblaciones campesinas; la conversión de diversas formas de derechos de propiedad -común, colectiva, estatal, etcétera- en derechos de propiedad exclusivos; la supresión del derecho de los bienes comunes; la transformación de la fuerza de trabajo en mercancía y la supresión de formas de producción y consumos alternativas; los procesos coloniales, neocoloniales e imperiales de apropiación de activos, incluyendo los recursos naturales; la monetarización de los intercambios y la recaudación de impuestos, particularmente de la tierra; el tráfico de esclavos; y la usura, la deuda pública y, finalmente, el sistema de crédito. El estado con su monopolio de la violencia y sus definiciones de legalidad juegan un rol crucial (Harvey, 2004: 8).

En ese marco se juegan las modalidades actuales de acumulación por desposesión en los procesos de gentrificación, turistificación y patrimonialización (9). Estos nos interesan en tanto procesos generadores de sentidos sociales que configuran 'valores' susceptibles de ser mercantilizados: he aquí la importancia del arraigo territorial donde el espacio aparece como ese 'vacío' a partir del cual se opera ideológicamente -ya que aparece como desprovisto de todo elemento, en especial conflictual- con el fin de 'revalorizarlos'. Los centros históricos, el patrimonio cultural, edilicio, los lugares de 'moda' destinados al ocio y el entretenimiento emergen como un siempre-así, casi como estado natural de la vida urbana. Como todo mito 
fundante, excreta sutilmente aquello que ha desposeído para configurar su lugar 'aurático' en la ciudad. Bensäid (2011) sigue la pista de Harvey sobre la acumulación por desposesión y afirma:

\begin{abstract}
Más allá de la apropiación de las materias primas, de los recursos energéticos, de la mano de obra barata, se extiende a la apropiación mercantil, por parte del turismo especialmente, de la historia cultural $\mathrm{o}$, además, al pillaje puro y simple de los patrimonios culturales. Emplea diferentes medios que van, de la coerción externa a la canibalización por la lógica mercantil de formas de actividad y producción que le escapan aun (trabajo doméstico, servicio a las personas, producción de subsistencia). Esta ofensiva de la acumulación neoliberal pasa evidentemente por la destrucción de derechos sociales existentes y por la criminalización de las resistencias populares... (Bensaid, 2011: 54).
\end{abstract}

Varias décadas después y del otro lado del continente europeo, en la capital cordobesa este proceso se replica. Gentrificación, turistificación y patrimonialización son dinámicas de gestión del territorio sólo en apariencia diferencial ya que confluyen en tanto operadores de sentido en diferentes fragmentos del territorio generando valores y territorialidades particulares. La forma 'acumulación por desposesión' sigue señalando el mecanismo predilecto por el cual el capital "se hace de las estructuras físicas y de los espacios de vida de los habitantes tradicionales para desarrollar sus actividades, expulsándolos" (Hiernaux y González, 2014: 63). El turismo aparece como organizador social que desposee a los residentes privilegiando a esos 'otros' dinamizadores económicos, culturales y políticos (los turistas/inversores), pero también como estrategia de comunicación política que permite ocluir los potenciales frentes de conflictividad social relacionados con este tipo de intervenciones.

\title{
Patrimonio urbano en Córdoba y sus modalidades expresivas. Gestión del territorio y cadena de valores
}

Seguimos aquí la concepción que realiza el pensador mexicano Víctor Delgadillo sobre patrimonio urbano, ya que nos permite dar cuenta de su carácter de operador simbólico:

El patrimonio urbano no es un acervo material preexistente sino una construcción social en la que tradicionalmente los grupos en el poder, desde un presente, seleccionan algunos de los múltiples inmuebles y partes de la ciudad del pasado. Así, la valoración de objetos 
producidos en el pasado remite a las relaciones que los pueblos y sus elites tienen con su historia remota y reciente (2015: 114).

Son múltiples las materialidades significantes que pueden configurarse en el soporte del patrimonio urbano (10) pero el constructo social que lo sostiene remite a ciertas relaciones políticas y económicas que configuran formas de sociabilidad en espacios urbanos singulares. Esta operación nos permite dar cuenta no sólo del carácter expresivo de todo el proceso, sino que nos insta a focalizar en los sentidos que se construyen sobre ciertos territorios con sus prácticas (de habitar, circular, disfrutar, conocer, etcétera) que otorgan un marco a las experiencias urbanas contemporáneas en tanto 'aceptables/deseables'. La idea de patrimonio condensa en sí, una serie de imaginarios sociales 'positivos' que se asocian al valor material o inmaterial de "las cosas" y que expresan aquello susceptible de ser resguardado/protegido para la posteridad por 'todos' pero, en el que intervienen sólo 'algunos'. Nutrido por el trasfondo de una memoria colectiva establecida como 'bien común' que se actualiza en el presente siempre de manera transparente y sin conflictos, hoy el patrimonio urbano también se plantea como algo a producir para el futuro (11): es esta dimensión socio-simbólica la que lo constituye en un claro operador ideológico de la discursividad política contemporánea.

En la última década, y con mayor intensidad en los siete años posteriores a los festejos por el Bicentenario de la Patria, Córdoba atraviesa un fuerte proceso de patrimonialización. Este proceso emerge en la escena pública como argumento de múltiples acciones e intervenciones destinadas a posicionarla como destino turístico nacional e internacional. Así, distintos proyectos urbanísticos posibilitaron la construcción, iluminación y remodelación de obras, monumentos y espacios públicos localizados en lugares considerados estratégicos dentro de la cartografía urbana. Bajo la lógica del embellecimiento, la ciudad comienza a perfilarse como una "Córdoba colonial" con notorias inversiones públicas en proyectos de "recuperación" y "restauración" y de una Córdoba aggiornada diversificando su mercado cultural y de consumos (12).

Esta orientación en las políticas públicas es presentada por la gestión estatal en la página web de la Municipalidad. Allí, "Patrimonio" tiene su propia pestaña de acceso -incluido dentro del rubro "Servicios"- que expresa el objetivo de "instrumentar mecanismos público-privados eficaces que garanticen la conservación, restauración y la rehabilitación de los edificios de patrimonio", con el fin de que "residentes y turistas de todo el mundo encuentran en las calles de la ciudad y en sus edificios públicos el gran valor arquitectónico" (web de la municipalidad). En la misma se expone cómo del concepto de "Patrimonio Urbano" se pasó al de "Patrimonio 
de la Ciudad" que involucra el patrimonio inmaterial, de suma importancia para "la construcción de la identidad ciudadana" (nota 1). En esta dirección, como veíamos, convergen las políticas de turismo y gentrificación de los territorios en el marco de una concepción de la ciudad guiada por el branding o 'marca' como identificación generadora de valores.

En concordancia con este proceso, las normativas municipales fueron modificadas: en junio de 2013, mediante la Ordenanza 12201 sancionada por el Concejo Deliberante, se modificó el Catálogo de Bienes Inmuebles y Lugares del Patrimonio Cordobés (13), y en noviembre del mismo año, se promulga la Ordenanza 12241 que regula el Patrimonio Cultural Intangible e Inmaterial de la Ciudad y fija el alcance de las declaraciones llamadas de interés municipal. Estos conceptos incluyen las manifestaciones, tradiciones, usos y costumbres, festividades, expresiones artísticas distintivas o características de cualquier índole, reconocidas por la comunidad cordobesa como parte del legado cultural e integrante de la propia identidad y diversidad cultural (14).

En el marco de esta apertura a la 'revitalización/recuperación' o 'puesta en valor', el estado provincial también viene participando en la generación de obras con potencial valor patrimonial. Tal es el caso del Parque y Puente del Bicentenario (nota 4); el Centro Cívico (2011); el Parque las Tejas (2011); la Plaza Juan Bautista Alberdi; el Paseo de la Amistad, la 'recuperación' de la Plaza Austria (2017), así como también la iluminación del recorrido histórico cultural la Media Legua de Oro (nota 5) (15).

Luego de presentar estas referencias acerca de la política patrimonial para el desarrollo urbano en la ciudad de Córdoba (16) proponemos el ejercicio analítico de pensar los procesos de patrimonialización en registros diferentes pero complementarios: los espacios, los potenciales destinatarios/consumidores, la modalidad de circulación de los cuerpos como indicadores de la relación indisociable entre turistificación, gentrificación y patrimonialización. Para ello analizaremos el caso del cuarteto y la gastronomía en Córdoba capital como orientaciones concretas en que la cultura y la historia se materializan en las piedras, en un trazado que articula la recuperación de prácticas y saberes 'típicamente cordobeses' con intervenciones localizadas.

El cuarteto fue declarado en 2013 Patrimonio Cultural de la ciudad por el Concejo Deliberante, y la Ley provincial 10174, sancionada ese mismo año, lo instituyó "como género folclórico musical propio, característico y tradicional de la provincia de Córdoba". Otras acciones vinculadas a la revalorización del ritmo popular fue el establecimiento por ley provincial del 4 de junio como "Día del Cuarteto" y del 12 de enero como el "Día del Piano Saltarín", en conmemoración del fallecimiento de la pianista Leonor Marzano (nota 6). En 2015 el Municipio 
anunció el avance en el trámite de la inclusión del cuarteto como Patrimonio Cultural Inmaterial de la Humanidad por la UNESCO, como una muestra de la orientación de las políticas de Estado y la estructuración de sus argumentos desde la recuperación/revalorización de los espacios, prácticas, objetos e historias 'cordobeses'. En este contexto, podemos observar a partir de dos acciones concretas vinculadas al cuarteto modalidades particulares de intervención urbanística en que la 'intangibilidad' del ritmo cordobés cobró materialidad en el espacio urbano.

Por una parte, la instalación de las esculturas de bronce de los músicos Rodrigo Bueno (nota 7) y la Mona Jiménez (nota 8) por el gobierno provincial en el Paseo del Buen Pastor en el Barrio de Nueva Córdoba (nota 9). La primera fue inaugurada en 2013, algunas horas antes del inicio del "Primer Carnaval Cuartetero" (17) y la segunda en 2015. Ambas obras fueron realizadas por el artista Fernando Pugliese, autor de las esculturas de Alberto Olmedo y Javier Portales ubicadas junto al Obelisco en la Capital Federal-. Por otra, la inauguración del Paseo de la Fama del Cuarteto en 2014 (nota 10) (18). Esta obra implicó la puesta en valor de la peatonal San Martín, entre la avenida Olmos y calle Santa Rosa en el microcentro cordobés. En ese tramo se colocaron placas con los nombres de los artistas cuarteteros más importantes Rodrigo Bueno, Carlos "La Mona" Jiménez, "Coquito" Ramaló, "Manolito" Cánovas, Carlos "Pueblo" Rolan y Gary-. Si bien ambas intervenciones pueden ser leídas como parte de un continuum en tanto apuntan a la recuperación de espacios, prácticas y figuras culturales que se inscriben como parte de un proceso de patrimonialización general, presentan sus especificidades por cuanto proponen destinatarios, modos de circulación y posibilidades de consumo diferentes.

Las esculturas de los músicos en el complejo cultural del Buen Pastor emergen en el marco de construcciones históricas, edificios de gran valor inmobiliario y propuestas gastronómicas situados estratégicamente para el turismo. Se presentan así, dispuestas para la observación, el detenimiento y el consumo de los "visitantes/turistas" (nota 11) que circulan por este espacio constituido como punto encuentro de referencia citadina, principalmente para jóvenes y turistas. Durante la inauguración de la escultura de la Mona Jiménez, el presidente de la Agencia Córdoba Turismo, Gustavo Santos, declaraba en alusión al músico homenajeado:

Carlitos es particular, una marca registrada de los cordobeses. Yo he visto rockeros, chicos a los que les gusta la música electrónica, que cuando están fuera el país y escuchan a La Mona, Iloran, aunque aquí no vayan a los bailes. Es bueno que él tenga la suerte de poder participar de este acto y ver en vida un monumento que además seguramente será un atractivo más de la ciudad (Nota 18, cursiva nuestra). 
El espacio urbano va configurándose, de esta manera, como opción posible y deseable para el mercado, una "marca" o "imagen" que ofrece un "mercado de experiencias" a partir de la patrimonialización y la reconversión urbana al servicio del turismo. No obstante, para ello es preciso detener el tiempo para recuperar la memoria colectiva de la cultura popular y volverla un "souvenir", lo que requiere extraer al género musical de su condición de origen, para renegociarlo como 'popular' y volverlo próximo y 'deseable' para aquellos cuyo estilo de vida no implica proximidad de clase con la práctica cuartetera.

Si nos desplazamos, desde la 'Córdoba Colonial' hacia el norte de la avenida Colón en el microcentro cordobés, en la calle San Martín, rodeado de comercios y vendedores ambulantes, se ubica Paseo de la Fama de Cuarteto. Esta ubicación, poco reconocida como recorrido turístico, se ofrece como paseo ya no destinado a los turistas/visitantes, sino a los transeúntes, dado que no son los turistas, sino los "peatones" vueltos turistas en su propia ciudad, quienes se "toman una foto" junto a la escultura de Leonor Marzano (nota 12). Ello implica la disposición de un paseo destinado para los transeúntes habituales que simula la forma monumento de otros emplazamientos y concreta la materia en la incorporación de un contenido (los cantantes del género) con relación a lo que se define como el gusto cultural de estas clases (Boito y Espoz, en prensa).

Otro fenómeno que se integra a este proceso de manera llamativa es la gastronomía, en tanto aparece inscripta en el diseño de los procesos de patrimonialización apelando a distintos criterios para su valoración estética y económica: autenticidad, unicidad y particularidad emergen como sus rasgos característicos configurando un lugar específico en que se conjugan modos del comer como parte de "paquetes de experiencias" (Debord, 1995).

En la ciudad y la provincia de Córdoba se vienen organizando de manera continua eventos gastronómicos, patrocinados por organismos estatales provinciales y municipales (nota 13) (19). En este contexto, se presenta como significativa la relación entre gastronomía y cultura, dado que la comida convertida en patrimonio cultural también parece operar como modalidad política para recuperar la memoria colectiva y poner en valor determinadas zonas, espacios y prácticas apelando a su importancia histórico-cultural.

De manera análoga al caso del cuarteto, la gastronomía se presenta como factor interviniente en los patrones de circulación organizados en diferentes ritmos, velocidades y circuitos a partir de las posibilidades de consumo de los sujetos. Por un lado se configuran polos gastronómicos, donde se enuncian propuestas culinarias vinculadas al buen gusto y la cocina gourmet, asociada a otros valores como el diseño de vanguardia, la creatividad y las 
propuestas trendy. Tal es el caso de Barrio Güemes, que se ofrece como parte del patrimonio colonial de Córdoba como punto final del recorrido por la antes mencionada "Media Legua de Oro". Este barrio, de edificios con "características arquitectónicas especiales", se constituye como "un punto de encuentro de artistas, músicos y escritores cordobeses que le dan una impronta pintoresca a esa zona..." (nota 14), abarca a más de cuarenta bares y restaurantes, a los que se suman las franquicias.

La construcción de la propuesta artístico-gastronómica de este sector implica la definición de un público objetivo presentado como turista-consumidor con un elevado nivel de gastos en materia de alojamiento, gastronomía y entretenimiento (nota 15 y 16) (20), al que se ofrece una propuesta gastronómica (los platos y bebidas se anuncian como obra de un chef o bartender particular, 'un autor') que se acompaña con un "ambiente" de estilo y/o decorado particular (21). Este paquete de consumo supone la planificación de la circulación (la liberación y facilitación de las vías de acceso), del detenimiento (en espacios que conjugan lo abierto -galerías y bares con terrazas- y lo cerrado -locales comerciales de diseño y decoración-) y de permanencia y consumo (la propuesta gastronómica y de entretenimiento).

Otro lugar significativo en que la comida aparece como de la identidad cordobesa es el Festival Mundial del Choripán, organizado por la Municipalidad de Córdoba. Allí participan los típicos carritos y restaurantes cordobeses ofreciendo diferentes versiones del sándwich autóctono (clásico, gourmet, molecular, para celíacos, representantes de otras ciudades cordobesas, y combinado con las especialidades de otros países como Cuba, Polonia, Croacia, Méjico y Países Árabes) y propuestas artísticas diversas. En 2017 este evento se presentó como el Festival Mundial del Humor y el Choripán cordobés (nota 17) (22) con entrada libre y gratuita. Según datos oficiales concurrieron más de 40 mil personas. La Secretaría de Cultura de la Municipalidad, reivindicó al masivo festival como un encuentro popular "que desacraliza la idea legítima de los espacios institucionales de la cultura (la solemnidad del museo), acercando a un público amplio y diverso a través de una propuesta popular, lúdica y participativa" (nota 17). Así, la comida típica emerge mediante una modalidad que invita a comer 'en familia', de pie frente al puesto de venta, a precios más accesibles y a vivir la gastronomía y la cultura como un visitante en la propia ciudad.

La música y la comida como parte del patrimonio cultural se despliegan como propuestas diferentes $-\mathrm{y}$ diferenciadoras- que invitan a recuperar la memoria y la tradición cordobesa: detenerse a contemplar las figuras del género popular cordobés o rememorar el cuarteto en medio del ritmo cotidiano; disfrutar la comida en medio "la historia y la tradición cordobesas" o recorrer con la familia el Festival del Choripán. Estos ejemplos nos permiten comprender la 
circulación y el detenimiento en el espacio/tiempo como acciones que performan la trama de interacciones, que inciden directamente en los territorios modificando los modos de habitar y las relaciones sociales. Pero además señalan procesos de 'acumulación por desposesión' en la revalorización inmobiliaria y el turismo urbano como factor económico cada vez más determinante (Hiernaux y González, 2015; Judd y Fainstein 1999) que desaloja y expropia a algunos de sus habitantes de sus espacios/prácticas tradicionales para ofrecerlos al turismo, a la vez que los convierte en visitantes de su propia ciudad.

\section{El turismo como estrategia de la comunicación política: la "transparencia" ideológica y nuevas formas de resistencia}

El turismo aparece así como uno de los argumentos claves de las principales estrategias e intervenciones urbanísticas del Estado y del mercado para reinventar la ciudad: la comunicación emerge como la variable común de gobiernos locales para instalar a las ciudades como imágenes-marcas en el mapa mundial. La idea de marca-país, marca-ciudad es el resultado del avance del citybranding como metodología estatal de gestión (23): vuelve comunicable no sólo los aspectos mercantilizables del territorio y todo lo hay en él (sea de índole 'natural', 'cultural', histórica') (24) sino, por sobre todo, el establecimiento de una experiencia de comunicación política vía NTIC's ideológicamente vinculada a la noción de transparencia y a los valores de desarrollo sustentable que se juegan tanto en el espacio físico, como en el espacio público (25). Como se puede evidenciar, aquí el carácter estratégico otorgado a la comunicación no es una atribución de sentido desde una mirada exotópica (los parisinos hacia Haussman) sino inherente a la práctica política actual. Como expone Quevedo:

\footnotetext{
En la ciudad de Córdoba, estos repertorios tecnológicos fueron adaptados a la gestión municipal y el Concejo Deliberante. El gobierno de la provincia de Córdoba, por su parte, montó sobre el sitio web "Ciudadano Digital" su principal escenario tecnológico de interacción social. Del mismo modo, otras ciudades cordobesas y del país se sumaron al modelo de gestión desde variadas etiquetas "inteligentes", herramientas que -sin importar el contexto- les permitieron organizar sus prácticas estatales en función al eje de la transparencia y la participación popular desde la horizontalidad de las plataformas 2.0. (2017: 153).
} 
Lo que aparece en las páginas web oficiales de los gobiernos municipales y provinciales como se ve en los apartados anteriores, consolida al turismo como valor que per se representa las dinámicas de organización del territorio donde 'aparecen' las voces de todos los actores involucrados, guiados por un consenso alcanzado por una "amplia participación" (a veces sólo virtual). Como estrategia de comunicación política, el turismo es ese valor común incuestionable que llevará a Córdoba al 'desarrollo y progreso' y se materializa en el reordenamiento material de la vida cordobesa sin conflictos ni cuestionamientos. Una mirada atenta, permite evidenciar algunas formas del conflicto que exceden este espacio de la comunicación como modalidad de información, que muchas veces roza la visibilización mediática, pero que en las trincheras del territorio se cocinan todos los días.

Hoy, lo que conocíamos como ocio y entretenimiento está instalado como clave de productividad que incide e impacta en el ordenamiento urbano, generando novedosas formas de rentabilidad y plusvalía donde el turismo aparece como "la" clave del desarrollo. La cultura aparece como ideologema que impulsa dinámicas de intervención estatal y privada que la postulan como 'marca', como 'imagen' que orienta la percepción idiosincrática de lo local, con trazados globales muchas veces contradictorios. Ello evidencia muchas veces una tensión entre las formas subjetivas del 'turista' frente al 'poblador', modificando continua y cotidianamente las dinámicas al interior del territorio.

Esta tendencia en la comunicación política, ocluye los procesos de gentrificación o turistificación, ya que estos términos hoy expresan un estado conflictivo de las intervenciones en el territorio que si bien remiten a conceptos del campo crítico-académico, se han instalado en la discursividad social con valor aceptable. Al referirnos a Barrio Güemes, principal centro de las intervenciones actuales, si bien se observa una activa intervención estatal en el sector (ex barrio Abrojal y Pueblo Nuevo) desde hace más de tres décadas (26) tanto las ordenanzas de regulación del suelo como el carácter estratégico asignado a la zona orientado al ocio y esparcimiento ha sido variable y contradictorio. Hoy podemos visualizar que se trata de un claro ejemplo de los procesos de gentrificación local (Pereyra, 2015; Bocolini y Kierschenmann, 2016) constituyendo una especie de 'laboratorio' de prácticas que pueden hacerse extensibles a otros espacios de la ciudad. El IPLAM, en su plan estratégico, prevé la creación de la "marca Güemes" que resalta valores patrimoniales para "incentivar la aparición de residencia [sic] o continuar reforzando el rol que comienza a adquirir de albergue temporal -del tipo hostel-". (Bocolini y Kierschenmann, 2016).

Si tomamos en consideración lo enunciado hasta aquí, el patrimonio urbano desde la perspectiva del turismo como forma estratégica de comunicación política, se observa que los 
sentidos creados se asocian a formas de acumulación por desposesión que garantizan la continua generación de rentabilidad (económica) de los territorios. Pero a la vez, se producen formas de valor social y cultural que inciden directamente en las tramas de sociabilidad local: los entornos creados por y para el turismo avanzan sobre las formas de interacciones espontáneas y heterogéneas de actores sociales locales. "Los grandes inversores" aparecen como aquellos a quienes está predestinado estos lugares tocados por la 'histeria patrimonial' (Peixoto, 2006) que muchas veces encubre procesos de gentrificación. Esto sólo se pone en jaque cuando el avance inmobiliario manifestado en la destrucción/demolición a lo Haussman, desnuda la frágil trama de aquellos que han optado por habitar una ciudad en la que todos podemos formar parte. Ese ha sido el lema de la Multisectorial "Defendamos Alberdi": "paren de demoler" atribuye sentidos y valores diferenciales con relación a la escala de interacción que supone carne y piedra.

\section{Notas}

(1) Entendemos turismo en sentido amplio como proceso que involucra diferentes dimensiones sociales que posibilitan incluso la sectorización del mismo (turismo académico, gastronómico, patrimonial, cultural, empresarial, etcétera), otorgándole una complejidad en tanto fenómeno. Por consiguiente, consideramos más pertinente trabajar con lo que algunos autores denominan procesos de 'turistificación' de la vida cotidiana (Lanfant, 1995; Hiernaux, 2000 y 2002).

(2) Existen abundantes discusiones en torno a la especificidad de estos tres procesos que, de acuerdo a la geopolítica, comportan caracteres difícilmente generalizables (Sequera, 2015; Delgadillo, 2015).

(3) Dice Benjamín: "(...) si los obreros usaban barricadas, Haussmann busca prevenirlas de dos maneras. La longitud de las calles hará imposible su construcción y nuevas vías enlazarán en línea recta los cuarteles con los barrios obreros. Los coetáneos bautizaron su empresa: "embellecimiento estratégico" (2007: 60).

(4) Este señalamiento, que hoy aparece como extraño, se vuelve significativo a la luz de la estricta semántica actual en torno a las 'grandes obras' y sus inauguraciones por parte del Estado.

(5) Reza la tesis 3: "El espectáculo se muestra a la vez como la sociedad misma, como una parte de la sociedad y como instrumento de unificación. En tanto que parte de la sociedad, es expresamente el sector que concentra todas las miradas y toda la conciencia. Precisamente porque este sector está separado es el lugar de la mirada engañada y de la falsa conciencia; y la unificación que lleva a cabo no es sino un lenguaje oficial de la separación generalizada".

(6) En esta línea son interesantes las hipótesis de Kurz en su Manifiesto contra el trabajo sobre el carácter estrictamente moral del trabajo -que identifica al nacimiento de la burguesía al igual que Debord-, tal como se ha configurado en la experiencia contemporánea: quien acepta la lógica del trabajo en contextos capitalistas como los nuestros, acepta al mismo tiempo la lógica del apartheid. "Todas las fracciones del campo trabajo, que abarca a todos los partidos, han aceptado hace tiempo secretamente esta lógica y colaboran con entusiasmo en la misma. Ya no discuten sobre si se empuja a los márgenes a partes cada vez más grandes de la población y se las excluye de toda participación social, sino sólo sobre cómo imponer esta selección” (Kurz, 1999: 4). 
(7) "La historia universal nació en las ciudades y llegó a su mayoría de edad en el momento de la victoria decisiva de la ciudad sobre el campo. Marx considera como uno de los mayores méritos revolucionarios de la burguesía el hecho de que "ha sometido el campo a la ciudad", cuyo aire emancipa. Pero si la historia de la ciudad es la historia de la libertad, lo ha sido también de la tiranía, de la administración estatal que controla el campo y la ciudad misma. La ciudad no ha podido ser hasta ahora más que el terreno de lucha por la libertad histórica, y no su posesión..." (Tesis 176). En la década que Debord escribe se dan los primeros movimientos 'ambientalistas' (Ios llamados 'Back to the land') como resultado de las principales consecuencias del desarrollo urbano en su complejidad.

(8) El autor identifica en la de década de 1970 la reconfiguración de las prácticas neoliberales que impactan directamente en la apropiación espacial del capital y que esquemáticamente remite a cuatro, hasta entonces, novedosas prácticas: la privatización, la financiarización, la gestión y manipulación de las crisis y redistribuciones estatales de la renta. Ya en los manuscritos de 1844, Marx exponía la particular relación existente entre las formas de territorialización de la acción y el carácter acumulativo del capital en tanto relación formal de finalidad "extractiva" vinculada en principio al carácter del trabajo humano (explicación de la acumulación originaria). Idea que instaura a la Economía Política como el argumento de "un origen" que va regir las relaciones entre "espacio", "tiempo" y "cuerpos" al menos desde el siglo XIX a esta parte, y donde las 'leyes económicas' operan mágicamente y son el designio de la desigualdad estructural.

(9) Podría establecerse cierto paralelismo -con los riesgos que ello conlleva- entre las formas de desposesión que describe Bensäid, retomando el problema de la acumulación originaria en Marx, y los vinculados a estos procesos, cuya tendencia cada vez más señala una forma de desposesión con respecto al hábitat, la cultura y las formas de disfrute en la vida contemporánea, que no pueden ser percibidas por fuera del fundamento de la propiedad privada. La mercantilización de la vida alcanza todos los dominios de la existencia.

(10) Entendemos estos procesos como operaciones semióticas: según Verón (1993) todo discurso social es una inversión de sentido en materias significantes, cualquiera sea su soporte. Así, el patrimonio urbano emerge como una discursividad cuyas materias significantes varían (edificios, objetos, sujetos, historias, prácticas) aun cuando aquí sólo focalicemos en ciertas modalidades expresivas del mismo.

(11) Muchas de las grandes obras de la ciudad, se inauguran bajo este designio: no solo se reconoce el patrimonio a partir de la revalorización sino que se produce 'patrimonio' para las futuras generaciones como el caso de las obras por los bicentenarios (Puente, Casa de Gobierno, Plazoleta del Bicentenario, etcétera).

(12) Con la implementación del Plan Director (2008-2020) se procedió a la "remodelación" de la zona céntrica de la ciudad ampliando calles y avenidas para el circuito turístico, la restauración de edificios antiguos y la creación de zonas para el entretenimiento.

(13) En esta normativa se reemplazó el Anexo I de la Ordenanza 11190. El nuevo listado incluye 1990 inmuebles con diferentes categorías de protección, 110 espacios que conforman el denominado 'patrimonio moderno' (plazas, calles, parques y puentes) y 180 inmuebles con autorización previa a la prohibición municipal de demoler, denominados en adelante 'patrimonio intervenido'.

(14) Entre éstos, se declara al cuarteto y al humor como patrimonio intangible cultural de los cordobeses.

(15) La Caminata la Legua de Oro es un itinerario de unas 25 cuadras por espacios de valor arquitectónico y artístico (centros culturales, museos, teatros y paseos) entre la Plaza San Martín, en el centro de la ciudad y el Parque Sarmiento. Se recomienda a los visitantes recorrerla de noche para apreciar monumentos y edificios puestos de relieve por juegos de luces que destacan estos espacios patrimoniales.

(16) El antecedente fundamental es el reconocimiento de la Manzana y las Estancias Jesuíticas, en la ciudad de Córdoba y diferentes puntos de la provincia, como Patrimonio de la Humanidad por UNESCO (2000). 
(17) El Carnaval del Cuarteto, definido como 'producto turístico cultural' instituido del 2013 al 2015 por el Gobierno provincial fue presentado como "una fiesta popular que busca poner en valor un ritmo que es componente de la identidad cultural de los cordobeses", según el texto oficial de la Agencia Córdoba Turismo, cuya intención fue replicar carnaval de Bahía en Córdoba reemplazando el ritmo brasilero axé por el cuarteto.

(18) Asimismo, se anunció la puesta en valor de la cuadra de San Martín entre Sarmiento y Santa Rosa mediante el ensanche de las veredas, la colocación de adoquines en los solados y nuevas luminarias.

(19) Los eventos considerados por el diario como más importantes del año fueron: Mionca (enero de 2016 y 2017), Peperina (marzo), Feria Ají Mercado Gourmet, Ñam (mayo), Expo Delicatessen \& Vinos y Córdoba Come (en junio y marzo de 2017).

(20) "Estamos haciendo valoraciones a partir de encuestas a turistas para conocer sus demandas y las personas comprendidas en este colectivo se caracterizan por el elevado nivel de gastos en alojamiento, gastronomía y entretenimiento".

(21) Tal es el caso de "La Cova del Drac" presentada como "una casona de principios del siglo 20, ambientada con antigüedades y objetos reciclados. Recomendable resto bar que combina una gastronomía de gran nivel y una alta coctelería que descansa en las manos del bartender más reconocido de la ciudad (Matías Leanez)".

(22) Al evento gastronómico se sumó la presentación de humoristas del programa cultural municipal "Tu Barrio en Escena", los ganadores del certamen y una zona de humor gráfico. También se proyectó un video con registro audiovisual de la revista cordobesa Hortensia.

(23) Según Roldán, Vera y Pascual (2015) esto emerge en la Argentina en el marco de una readecuación estructural y política del Estado en vistas a flexibilizarse para garantizar la circulación de los flujos de capital. En este contexto se instala el lexema "gobiernos locales" (hoy materializados en la Red Mercociudades, por ejemplo) como expresión de un tipo de institucionalidad cuya autonomía descomprime las "duras" estructuras de la concepción fordista estatal: "Se incorpora el planeamiento estratégico, herramienta empleada originalmente por el sector empresarial de elite (Gahan, 2005), a la lógica de gubernamentalidad de los municipios. Este artefacto cultural movilizó nuevas significaciones que, con mayor o menor transparencia, se enmarcaban dentro de la matriz de sentidos neoliberal. Para ello, y como complemento de la mentada estrategia de planeamiento, se adoptó el marketing y la publicidad como perspectiva comunicacional apropiada para construir la imagen de ciudad basada, también, en la lógica empresarial. Se planteó la necesidad de que las ciudades crearan su marca" (2015: 54).

(24) Es interesante señalar aquí la aparente a-conflictividad que se presenta a la hora de (re) valorizar aspectos de la vida histórica, social o cultural de un país. El valor, aparece como valor en sí mismo, casi emulando el carácter de la propia mercancía en configurarse como tal (desvinculada de la fuerza de trabajo que la produjo). Pensemos sólo en el caso cordobés donde lo 'colonial' adquiere aires de ensoñación fantasiosa- más que fantasmal- del pasado de colonización genocida: el centro 'histórico' como momento fundacional de la urbe borra todas las marcas de las condiciones de producción que hicieron posible su constitución. En este sentido, la crítica ideológica aparece como una clave de lectura que permite -en una hermenéutica siempre compleja- restituir a cada documento de civilización su barbarie. El 'mito' de fundación de las ciudades colonizadas por los españoles se repite casi con naturalidad en toda la publicidad de nuestra Córdoba turística, horadando las propias experiencias de sus pobladores en relación a la configuración conflictiva de su historia.

(25) En la tesis de Delgado y Malet sobre el espacio público como ideología (2007) queda clara esta tensión: "El ciudadanismo es, hoy, la ideología de elección de la socialdemocracia, que, como escribía María Toledano (2007), lleva tiempo preocupada por la necesidad de armonizar espacio público y capitalismo, con el objetivo de alcanzar la paz social y "la estabilidad que permita preservar el modelo de explotación sin que los efectos negativos repercutan en su agenda de gobierno". Pero el ciudadanismo es también el dogma de referencia de un conjunto de movimientos de 
reforma ética del capitalismo, que aspiran a aliviar sus efectos mediante una agudización de los valores democráticos abstractos y un aumento en las competencias estatales que la hagan posible, entendiendo de algún modo que la exclusión y el abuso no son factores estructurales, sino meros accidentes o contingencias de un sistema de dominación al que se cree posible mejorar éticamente".

(26) PLANDEMET (1980); PEC (1993-1999); PECba (2003-2006); "Portal Güemes” (2009); Plan Director (2008) y Plan Director Córdoba 2020 (2015).

\section{Bibliografía}

Benjamin, W. (1972). Iluminaciones I. España: Taurus.

Bensäid, D. (2011). Los desposeídos, Karl Marx, los ladrones de madera y los derechos de los pobres. Buenos Aires: Prometeo.

Boccolini, S. y Kierschenmann, C. (2016). Visibilizando procesos de gentrificación en Córdoba, Argentina: El caso de barrio Güemes. Ponencia presentada en el Congreso Contested Cities. Contested Cities, Madrid. Recuperado de https://bit.ly/2OKxhkn

Boito, M. E. y Espoz, M. B. (en prensa). Disputas sobre "lo común": políticas de patrimonio, conflictos y haceres colectivos. En Echavarría, C. y Abatedaga, N. (comp.). Lo común en la construcción de ciudad. Córdoba: CONICET y Universidad Nacional de Córdoba.

Debord, G. ([1967]1995). La sociedad del espectáculo. Buenos Aires: La Marca.

Delgadillo, V. (2015). Patrimonio urbano, turismo y gentrificación. En Delgadillo, V.; Díaz, I. y Salinas, L. (coords.). Perspectivas del estudio de la gentrificación en México y Latinoamérica, Serie Libros de investigación. México: Contested cities, UNAM.

Delgado Malet, D. (2007). El Espacio Público como Ideología. Jornadas Marx siglo XXI, Universidad de la Rioja, Logroño.

Espoz, M. B. (2013). Los 'pobres diablos' de la ciudad colonial... Imágenes y vivencias de jóvenes en contextos de socio-segregación. Buenos Aires: Estudios Sociológicos Editora. Recuperado de https://issuu.com/cieseditora/docs/los_pobres_diablos/1

Hiernaux, D. y González, C. (2014). Turismo y gentrificación: pistas teóricas sobre una articulación. Revista de Geografía Norte Grande, 58, pp. 55-70.

Hiernaux, D. (2000). La fuerza de lo efímero. Apuntes sobre la construcción de la vida cotidiana en el turismo. Lindón, A. (Coord.) La vida cotidiana y su espacio-temporalidad (pp. 95122). España: Anthropos.

Kurz, R. (1999). Manifiesto contra el trabajo, Grupo Krisis, Alemania. Recuperado de http://www.krisis.org/1999/manifiesto-contra-el-trabajo/ 
Harvey, D. (2004). El 'nuevo' Imperialismo: acumulación por desposesión. En Red de Bibliotecas Virtuales de CLACSO, Buenos Aires. Recuperado de http://biblioteca.clacso.edu.ar/clacso/se/20130702120830/harvey.pdf

Lanfant, M. (1995). International Tourism: identity and change.London: Sage Publications.

Peixoto, P. (2010). A cidade e a cultura do consumo: dos grandes armazéns a os centros comerciais. Câmara Municipal de Coimbra (org.). Caminhos e Identidades da modernidade. 1910, o edifício do chiado em Coimbra (pp. 69-82).Coimbra: Câmara Municipal de Coimbra.

Peixoto, P. (2013). A cidade performativa na era da economia das experiências. In Fortuna, C.; Bógus, L.; Corá, M. e Junior, J. (orgs.). Cidade e Espetáculo-A cena teatral lusobrasileira contemporânea (pp. 141-151). São Paulo: EDUC.

Pereyra, A. S. (2015). El espacio público: revalorización y transformaciones en el Paseo de las Artes, ciudad de Córdoba. Cardinalis, Revista del Departamento de Geografía, 3(4), pp. 91-111.

Quevedo, C. (2017). La transparencia como ideología. Régimen escópico y paquetes gubernamentales. En Espoz, M. B. (editora). Sentires (in)visibles. La construcción de entornos en contextos socio-segregados. Buenos Aires: Teseo.

Roldán, D.; Vera, P. y Pascual, C. (2015). La construcción escenográfica de la ciudad. Espacio público, turismo e itinerarios en Rosario (Argentina). Revista Chasqui, 130, CIESPAL, Ecuador, pp. 199-219.

Sennett, R. (2007). Carne y Piedra: El Cuerpo y la Ciudad en la Civilización Occidental, España: Alianza Ed.

Sequera, J. (25 de julio de 2015). A 50 años del nacimiento del concepto de 'gentrificación'. La mirada anglosajona. Biblio3w, Revista bibliográfica de Geografía y Ciencias Sociales, $X X(1127)$, Universidad de Barcelona, España.

\section{Fuentes digitales consultadas}

Nota 1 (s.f). Mi ciudad me incluye. Municipalidad de Córdoba. Recuperado de http://www.cordoba.gob.ar/programas/mi-ciudad-me-incluye/\#la-cultura-me-incluye

Nota 2 (27 de junio de 2013). Ordenanza Nro. 12201, Digesto Municipalidad de Córdoba. Recuperado de http://servicios.cordoba.gov.ar/DigestoWeb/Page/Documento.aspx?Nro=39091 
Nota 3 (7 de noviembre de 2013). Ordenanza Nro. 12241, Digesto Municipalidad de Córdoba. Recuperado http://servicios.cordoba.gov.ar/DigestoWeb/Page/Documento.aspx?Nro=41618

Nota 4 (21 de diciembre de 2010). Córdoba tiene su paseo del Bicentenario La Voz del Interior. Recuperado de http://www.lavoz.com.ar/ciudadanos/cordoba-tiene-su-paseo-delbicentenario

Nota 5 (23 de octubre de 2015). La media legua de oro: espectáculo, artes y patrimonio en el centro de Córdoba. Perfil. Recuperado de http://turismo.perfil.com/46711-la-medialegua-de-oro-espectaculo-artes-y-patrimonio-en-el-centro-de-cordoba

Nota 6 (15 de julio de 2014). Cuarteto, patrimonio mundial de la Humanidad. La Voz del Interior. Recuperado de http://www.lavoz.com.ar/ciudadanos/cuarteto-patrimoniocultural-de-la-humanidad

Nota 7 (16 de enero de 2013). Inauguran Estatua de Rodrigo Bueno en el Buen Pastor. La Voz del Interior. Recuperado de http://vos.lavoz.com.ar/bailes-cuarteto/inauguran-estatuarodrigo-bueno-buen-pastor

Nota 8 (3 de diciembre de 2015). "La Mona" ya tiene su escultura en el Buen Pastor. Cadena 3. Recuperado de http://www.cadena3.com/contenido/2015/12/03/La-Mona-ya-tiene-suescultura-en-el-Buen-Pastor-155318.asp

Nota 9 (23 de abril de 2017). Paseo del Buen Pastor: cultura y recreación en la ciudad de Córdoba. Córdoba Turismo de la Provincia. Recuperado de http://www.cordobaturismo.gov.ar/paseo-del-buen-pastor-cultura-y-recreacion-en-laciudad-de-cordoba/

Nota 10 (15 de julio de 2014). La peatonal San Martin ya es cuartetera. La Voz del Interior. Recuperado de http://www.lavoz.com.ar/ciudadanos/la-peatonal-san-martin-ya-escuartetera

Nota 11 (s.f.). Paseo del Buen Pastor. Córdoba Cultura. Recuperado de http://www.cba.gov.ar/cordoba-cultura/paseo-del-buen-pastor/

Nota 12 (12 de junio de 2015). La estatua de Leonor Manzano llega al Paseo de la Fama Cadena $3 . \quad$ Recuperado de http://www.cadena3.com/post_ampliadomobile.asp?post=147007\&titulo=La-estatua-deLeonor-Marzano-llego-al-Paseo-de-la-Fama\&resw=1440\&resh=836

Nota 13 (19 de junio de 2016). Ñam! Feria Gastronómica: todo lo que tenés que saber. La Voz del Interior. Recuperado de http://vos.lavoz.com.ar/comer-y-beber/nam-feriagastronomica-todo-lo-que-tenes-que-saber 
Nota 14 (22 de enero de 2017). Córdoba y su patrimonio colonial nos atrae tanto de día como de noche Diario La Nueva Recuperado de http://www.lanueva.com/turismo/891649/cordoba-y-su-patrimonio-colonial-nos-atraetanto-de-dia-como-de-noche.html

Nota 15 (29 de enero de 17). Córdoba: fuera del circuito de turismo diverso. La Voz del Interior. Recuperado de http://www.lavoz.com.ar/ciudadanos/cordoba-fuera-del-circuito-deturismo-diverso

Nota 16 (3 de marzo de 2017). Con mucho chimi y humor cordobés: así será el cuarto mundial del Choripán. La Voz del Interior. Recuperado de http://vos.lavoz.com.ar/comer-ybeber/con-mucho-chimi-y-humor-cordobes-asi-sera-el-cuarto-mundial-del-choripan

Nota 17 (s.f.). Después de esta $3^{\underline{a}}$ edición, el año próximo tendremos un Festival Mundial del choripán y el humor cordobés. Agenda Cultural, Municipalidad de Córdoba. Recuperado de http://cultura.cordoba.gov.ar/2016/03/despues-de-esta-3a-edicion-elano-proximo-tendremos-un-festival-mundial-del-choripan-y-el-humor-cordobes/

Nota 18 (3 de diciembre de 2015). "La Mona" ya tiene su escultura en el Buen Pastor. Cadena3. Recuperado de https://cadena3.com 